The Myth of the Angry Atheist

Brian P. Meier ${ }^{1}$, Adam K. Fetterman ${ }^{2}$, Michael D. Robinson ${ }^{2}$, and Courtney M. Lappas ${ }^{3}$

\author{
${ }^{1}$ Gettysburg College \\ ${ }^{2}$ North Dakota State University \\ ${ }^{3}$ Lebanon Valley College
}

Address correspondence to Brian P. Meier, Department of Psychology, Gettysburg College, Gettysburg,PA, 17325, USA; bmeier@gettysburg.edu. 


\begin{abstract}
Atheists are often portrayed in the media and elsewhere as angry individuals. Although atheists disagree with the pillar of many religions, namely the existence of a God, it may not necessarily be the case that they are angry individuals. The prevalence and accuracy of angry-atheist perceptions were examined in 7 studies with 1,677 participants from multiple institutions and locations in the U.S. Studies 1-3 revealed that people believe atheists are angrier than believers, people in general, and other minority groups, both explicitly and implicitly. Studies 4-7 then examined the accuracy of these beliefs. Belief in God, state anger, and trait anger were assessed in multiple ways and contexts. None of these studies supported the idea that atheists are particularly angry individuals. Rather, these results support the idea that people believe atheists are angry individuals, but they do not appear to be angrier than other individuals in reality. Keywords: anger, atheism, atheist, belief in God, personality, stereotypes
\end{abstract}




\section{The Myth of the Angry Atheist}

Most people in the U.S. believe in God. A 2008 survey of 35,000 Americans found that approximately $95 \%$ of people believe in God (Pew Research Center, 2008). The percentage of people who espouse a belief in a God varies widely across countries (Zuckerman, 2007, 2009) and even though there are hundreds of millions of non-believers wordwide (Zuckerman, 2007; Newport, 2011), they represent a minority. The term "atheist" is generally used to describe individuals who, given the available evidence, conclude that there are no Gods or creators, and the term "agnostic" is used to describe people who are unsure, undecided, or apathetic about the existence or non-existence of a God or a creator (Zuckerman, 2009). The focus in this paper is on people's belief or disbelief in God (e.g., believers, atheists, \& agnostics) and their perceived and actual anger levels.

Atheists are a minority group in the U.S. Typically, overt discrimination or unjustifiable negative behavior toward minorities is not explicitly tolerated in many societies (e.g., in regards to race or gender). However, discrimination against atheists appears to be somewhat acceptable. For example, atheists are distrusted (Gervais, Shariff, \& Norenzayan, 2011) and considered to be lacking in morality (Zuckerman, 2009). More consequential, less than 50\% of Americans state that they would vote for an atheist presidential candidate (Jones, 2007) and 48\% of individuals in one sample said they would disapprove if their child chose to marry an atheist (Edgell, Gerteis, \& Hartmann, 2006). Another study found that people would discriminate against atheists in important medical treatments (Furnham, Meader, \& McClelland, 1998).

Discrimination can be rationalized on the basis of the supposed undesirable stereotypes or generalized beliefs about a given group of people. For example, the belief that obese people are lazy and lacking in personal responsibility may bolster the tendency to discriminate against them 
(Puhl \& Heur, 2010). Stereotypes can also lead to a type of self-fulfilling prophecy that has been labeled "stereotype threat" (Spencer, Steele, \& Quinn, 1999). For example, the belief that women are worse at math compared to men can actually cause women to perform more poorly on math exams (Spencer et al., 1999). Therefore, identifying and correcting inaccurate stereotypes could be a useful strategy in reducing the negative outcomes of stereotypes. In this paper, we examine the prevalence and accuracy of an angry-atheist stereotype.

One potential stereotype about atheists is that they are particularly angry individuals. Countless media reports, internet postings, interviewers, and authors have used the angry-atheist label (e.g., Adams, 2011; Gellman, 2006; Lurie, 2010; Shaha, 2010, Vegano, 2011). A selfproscribed atheist has even written a book that attempts to explain why atheists are so angry (Christina, 2012). A general theme in these anecdotal examples is that atheists are particularly angry people, and that they challenge religion and believers in an angry and confrontational manner. Advocates of a "New Atheist" movement (e.g., atheist groups and well known commentators like Richard Dawkins or Sam Harris) challenge religion and the existence of a creator in a passionate manner, and they do so in more public settings than the more underground conversations of atheists from the past. Such public discussions may contribute to the general perception that, overall, atheists are exceptionally angry individuals. On the basis of such confrontational case examples and media depictions, but also in part to justify discriminatory behavior, we hypothesized that atheists would be viewed as angrier than other individuals (which is a systematic focus of Studies 1-3 of our investigation).

Researchers have examined stereotypes about atheists (e.g., Ehrlich \& Van Tubergen, 1971; Gervais et al., 2011) as well as relations between religiosity and mood (e.g., Diener, Tay, \& Myers, 2011; Jonas \& Fischer, 2006; Koenig \& Larson, 2001; Shreve-Neiger \& Edelstein, 
2004), but we are unaware of any work that has specifically examined stereotypes about anger and belief in God or the actual relationship between these variables. Some stereotypes have a basis in reality. Research shows some support for the "beauty is good" stereotype linking attractiveness to friendliness (Meier, Robinson, Carter, \& Hinsz, 2010). We suspect that the angry-atheist stereotype, if it exists and is robust, is unlikely to be a stereotype of this type. Media portrayals of the angry atheist almost surely focus on confirmatory cases and ignore cases that disconfirm the stereotype. As such, these confirmatory cases are unlikely to characterize the behaviors of the average non-believer. One's doubt about the existence of God is likely motivated by other considerations rather than anger or hostility. Religion can be a touchy subject to both believers and non-believers, but touchiness in this context need not imply touchiness in others. For all of these reasons, we doubted whether atheists would be angrier than believers (a focus of Studies 4-7 of our investigation).

All told, then, we expected greater myth than reality to the angry-atheist stereotype. The value of this work is both scientific and potentially societal. Negative stereotypes fuel discriminatory behavior (Correll, Park, Judd, \& Wittenbrink, 2002) and misperceptions of anger can engender hostile behaviors on the part of perceivers (Orobio de Castro, Veerman, Koops, Bosch, \& Monshouwer, 2002), both of which are problematic outcomes. By both documenting and disconfirming the angry-atheist stereotype, then, it is possible that our findings could contribute to a more civil discourse between believers and non-believers who are informed of such findings.

\section{Overview of Studies}

Studies 1-3 focus on the question of whether people ascribe higher levels of anger to atheists than to believers or people in general. Studies 4-7 focus on the question of whether there 
is in fact a relationship between people's belief in God and their levels of trait and state anger. Both questions will be pursued in multiple ways with different types of designs for the sake of comprehensiveness.

\section{Study 1}

Study 1 sought to determine whether people perceive atheists to be angrier than theists (i.e., people who belief in a God). We asked people to rate the average level of anger of both atheists and theists. We hypothesized that people would rate atheists as angrier than theists.

\section{Method}

Participants. Participants were 93 individuals (58 females; age $M=36.82$ years; $S D=$ 12.82 years). The self-reported race breakdown of participants was as follows: $87.10 \%$ Caucasian, 4.30\% African-American, 4.30\% Asian or Pacific Islander, 2.15\% Hispanic, 1.10\% American Indian or Alaskan Native, and $1.10 \%$ mixed race.

Materials and Procedure. Participants were recruited from Amazon.com's Mechanical Turk, which has been shown to be a valid way to collect online data (Paolacci, Chandler, \& Ipeirotis, 2010). The advantages of this recruitment procedure are diversity in age and geographical location. Participants were asked two straightforward questions that examined their explicit beliefs about the anger of atheists and theists. They were asked to rate the level of anger of the average atheist ("I think the average atheist - a person who does not believe in God - is") and believer ("I think the average theist or believer - a person who believes in God - is") using a 7-point scale ( 1 = not at all angry; 7 = very angry). In addition to the questions about atheists and believers, participants completed a number of questionnaires that were not relevant to the present study. 


\section{Results and Discussion}

Participant gender did not interact or modify the findings in any of the studies so we do not discuss it. We used a paired-samples $t$-test to determine if the perceived level of anger differed for atheists and theists. Atheists were perceived to be angrier $(M=3.48 ; S D=1.49)$ than theists $(M=2.37 ; S D=1.26), t(92)=5.80, p<.001, d=0.60$. Study 1 provided initial support for an angry-atheist stereotype in people's explicit beliefs.

\section{Study 2}

People are sometimes reluctant to explicitly (consciously and in self-reported terms) endorse negative beliefs about minority groups (Greenwald et al., 2002). For this reason, it is useful to assess stereotypes based on group membership using implicit (possibly unconscious, performance-based) measures as well (Greenwald et al., 2002). Implicit measures examine associations between concepts without directly or explicitly asking participants for such information with the goal of ascertaining an accurate picture of people's beliefs about sensitive subjects such as racial attitudes (Fazio \& Olson, 2003). Following this literature, Study 2 sought to examine if, and the extent to which, the angry-atheist stereotype characterizes implicit associations in addition to self-reported beliefs (i.e., the results of Study 1). To examine this question, we used the implicit association test (IAT), which has been used in hundreds of studies and has displayed admirable levels of predictive validity (Greenwald, Poehlman, Uhlmann, \& Banaji, 2009). We hypothesized that participants would display implicit associations consistent with the angry-atheist stereotype.

\section{Method}

Participants. Participants were 111 North Dakota State University undergraduates (52 females; age $M=19.38$ years; $S D=1.88$ years). The original sample included 115 participants, 
but 4 participants were dropped because of incomplete data or task errors. The self-reported race breakdown of participants was as follows: $73.00 \%$ Caucasian, $13.50 \%$ African-American, $8.10 \%$ Asian or Pacific Islander, $1.80 \%$ Hispanic, $1.80 \%$ American Indian or Alaskan Native, $0.90 \%$ Creole, and $0.90 \%$ non-report.

Materials and Procedure. Participants completed an IAT and answered demographic questions in private rooms with computers. The IAT is used to examine associations among concepts in an indirect manner (Greenwald, McGhee, \& Schwartz, 1998). Our version of the IAT required participants to categorize randomly presented words in terms of four categories: atheist, believer, angry, and calm. We used the word "atheist" for the atheist category and the word "believer" for the believer category as these words directly targeted the categories of interest and there are few synonyms. With respect to the angry versus calm distinction, five angry (angry, annoyed, bitter, hostile, \& irritable) and five calm (calm, easygoing, peaceful, relaxed, \& restful) words were presented in different trials. The latter comparison category was used because calmness is antithetical to anger (Berkowitz, 1993).

Across numerous trials, participants were asked to categorize a randomly presented word quickly and accurately one at a time. Category names appeared on the upper left and right of a screen. Individuals pressed the "q" key of the keyboard if the word belonged to the category (or categories) on the left and the "p" key of the keyboard if the word belonged to the category (or categories) on the right. Incorrect categorizations (e.g., categorizing the word "hostile" as a “calm" word instead of an "angry" word) were followed by the word INCORRECT in red font for 1,500 milli-seconds (ms) or 1.50 seconds. Correct categorizations were followed by a 150 ms blank screen until the next word appeared. 
The IAT had five blocks; three of them were practice blocks. The critical comparison was between block 3, which included the combined compatible categories of "believer-calm" and "atheist-angry", and block 5, which included the combined incompatible categories of "believer-angry" and "atheist-calm". In these blocks, two categories were mapped onto one response button. For example, in block 3, participants pressed the "q" key if the word presented on any given trial was "believer" or had a calm meaning (e.g., peaceful), but they pressed the "p" key if the word presented on any given trial was "atheist" or had an angry meaning (e.g., annoyed). In block 5, participants pressed the " $q$ " key if the word presented on any given trial was "atheist" or had a calm meaning, but they pressed the "p" key if the word presented on any given trial was "believer" or had an angry meaning. The purpose of these blocks was to determine if participants were faster when atheist-angry and believer-calm were paired (block 3) compared to when atheist-calm and believer-angry are paired (block 5). In the IAT, blocks with faster average categorizations times are a sign of associations that are formed in memory. Participants completed 60 trials in each of these blocks.

We administered the compatible block involving atheist-angry and believer-calm before the incompatible block involving atheist-calm and believer-angry. A meta-analysis has established that variations in the order of compatible and incompatible blocks minimally influence the size of implicit associations as determined by the IAT (Nosek, Greenwald, \& Banaji, 2005).

\section{Results and Discussion}

Quantification procedures were consistent with the original IAT (Greenwald et al., 1998). We deleted inaccurate trials (7.2\% of trials) and replaced trials faster than $300 \mathrm{~ms}$ or slower than 3,000 ms with these actual values. In other words, all trials slower than $300 \mathrm{~ms}$ were recoded to 
$300 \mathrm{~ms}$ and all trials faster than 3,000 ms were recoded to 3,000 ms. A log-transformation was then performed to reduce the positive skew inherent to reaction-time data. Analyses were performed on log-transformed values, but results are reported in terms of ms for ease of interpretation. We used a paired-samples $t$-test to examine categorization times by block type. Participants were much faster categorizing words in the atheist-angry/believer-calm block $(M=$ $742 \mathrm{~ms} ; S D=106 \mathrm{~ms})$ than in the atheist-calm/believer-angry block $(M=984 \mathrm{~ms} ; \mathrm{SD}=170 \mathrm{~ms})$, $t(110)=-19.61, p<.001, d=-1.86$. The effect size for this result was large suggesting that the angry-atheist stereotype appears robust in terms of implicit associations.

Studies 1 and 2 provide evidence for a stereotype in which atheists were viewed as angrier compared to believers. This conclusion would be bolstered if replicated with a different block order, but it is unlikely that a different result would have been found given prior results (Greenwald et al., 1998; Nosek et al. 2005). Nonetheless, the invariant block order chosen could be viewed as a limitation of Study 2 or at least an area for future investigation. All told, then, people appear to associate atheism with anger in terms of implicit associations.

\section{Study 3}

In Study 3, we sought to replicate and extend the results from Studies 1 and 2 in a number of ways. First, in order to ensure that the results from Studies 1 and 2 were reliable and generalizable, we collected data from a nationally representative sample of participants from the U.S. who were recruited by the survey company Qualtrics. Second, the comparison group for Studies 1 and 2 was believers or theists. Although the vast majority of Americans are in fact believers in God (Pew Research Center, 2008), it is possible that this label rendered anger judgments (or implicit associations involving anger) lower than they otherwise might be. Accordingly, the control target group for Study 3 was "people in general". We hypothesized that 
atheists would be rated as angrier than people in general, thus confirming a particular sort of link between perceptions of atheists and the emotion of anger.

Third, we wanted to establish that ascriptions of anger to atheists do not occur simply because of the minority status of this group. To make this point, Study 3 included another minority target group - gay and lesbian individuals - for comparison purposes. This comparison group is similar in size and familiarity to the atheist group and has been used effectively in previous stereotype research (e.g., Gervais et al., 2011). We hypothesized that participants would perceive atheists to be angrier than gay and lesbian individuals, which are results that would support the specificity of the angry-atheist stereotype. Study 3 also assessed participants' own beliefs in God as a potential moderating factor.

\section{Method}

Participants. Participants were 196 individuals (99 females; age $M=45.09$ years; $S D=$ 16.28 years). The self-reported race breakdown of participants was as follows: $73.50 \%$ Caucasian, 10.20\% African-American, 9.20\% Hispanic, 6.60\% Asian or Pacific Islander, and $0.50 \%$ no answer. As an indicator of the national scope of the data collection effort, responses were obtained from participants in 40 different states.

Materials and Procedure. The participants completed a number of questionnaires, many of which were not relevant to the present study. The participants were asked three questions that examined their explicit beliefs about the anger of atheists, people in general, and gay and lesbian individuals ( $1=$ not at all angry; $7=$ extremely angry). They later also completed a single-item belief in God scale. They were asked to answer this question: I believe God exists $(1=$ strongly disagree; $5=$ neither disagree nor agree; $9=$ strongly agree $)$. Singleitem continuous belief in God measures like this one are frequently used in the religiosity 
literature to assess the extent to which people believe in God (Gervais \& Norenzayan, 2012a; Inzlicht \& Tullett, 2010; Shariff \& Norenzayan, 2007).

\section{Results and Discussion}

The mean of the single-item belief in God measure was $7.32(S D=2.35)$. We examined anger perceptions by group (i.e., atheists, people in general, and gay and lesbian individuals) and belief in God ( $z$-scored) using a General Linear Model analysis. The main effect of belief in God was not significant, $F(1,194)=3.01, p=.08$. Both the main effect of group, $F(2,388)=24.40$, $p<.001$, partial eta squared $=.11$, and the interaction between group and belief in God, $F(2$, $388)=11.96, p<.001$, partial eta squared $=.06$, were significant. We ran multiple pairedsamples $t$-tests in order to examine the target group main effect. Participants rated atheists as angrier $(M=4.35 ; S D=1.55)$ than people in general $(M=3.95 ; S D=1.31), t(195)=3.16, p=$ $.002, d=0.23$, and gay and lesbian individuals $(M=3.51 ; S D=1.55), t(195)=7.01, p<.001, d$ $=0.51$. Gay and lesbian individuals were perceived to be less angry than people in general, $t(195)=-3.50, p=.001, d=-0.25$, which is interesting, but not particularly relevant to the predictions in the current study.

The procedures of Aiken and West (1991) were used to understand the significant interaction. As shown in Figure 1, participants scoring high $(+1 S D)$ in belief in God rated atheists as angrier than people in general, $F(1,194)=33.59, p<.001$, partial eta squared $=.15$, and the gay and lesbian target group, $F(1,194)=36.14, p<.001$, partial eta squared $=.16$, with no difference between the latter two groups, $F<1$. The pattern differed somewhat for those participants scoring low (-1SD) in belief in God. At this low level of belief, estimated means did not differ for the atheist and people in general target groups, $F<1.20$, though the gay and lesbian target group was perceived to be less angry than atheists, $F(1,194)=16.27, p<.001$, 
partial eta squared $=.08$, and people in general, $F(1,194)=23.32, p<.001$, partial eta squared $=$ .11.

As might be expected, then, the tendency to perceive atheists as angrier than people in general was more pronounced at higher levels of belief in God. Irrespective of belief in God, though, atheists were perceived to be angrier than both people in general and a comparison minority group, thereby replicating and extending the results of Studies 1 and 2. The latter result is an important one in suggesting that there is some specificity to the angry-atheist stereotype, though other target group comparisons might be used in the future.

\section{Study 4}

Studies 1-3 establish the existence of an angry-atheist stereotype. In Studies 4-7, we examined whether this stereotype is accurate. Studies 4-7 could quite conceivably involve null effects. Although any particular null effect might be questioned, we took steps to ensure that appropriate conclusions could be drawn. Convergence across studies was emphasized, and beliefs in God and experiences of anger were assessed in multiple ways. In addition, the sample sizes were such that the statistical power was in the range of approximately .70 to .80 , which is sufficient to detect a medium effect. Therefore, the power of these studies was adequate (Aron, Aron, \& Coups, 2009; Cohen, 1992).

Study 4 offers perhaps the strongest test of the angry-atheist hypothesis because participants were asked to categorize their religious affiliation (i.e., one's self identification of being an atheist, Christian, etc.). Few individuals self-identify as atheists in a strict sense of the term (Pew Research Center, 2008). Accordingly, a large sample size was collected to identify such individuals. Participants completed a trait anger scale and categorized their religious affiliation. Three different results are possible: (1) atheists score higher in trait anger than 
believers, (2) atheists score lower in trait anger than believers, (3) or atheists do not differ in trait anger compared to believers.

\section{Method}

Participants. Over several semesters from 2007 to 2012, we recruited 1,009 Gettysburg College undergraduates (612 females; age $M=18.94 ; S D=2.03$ years). The self-reported race breakdown of participants was as follows: $89.10 \%$ Caucasian, 3.80\% African-American, 3.20\% Asian or Pacific Islander, 2.20\% Hispanic, .20\% American Indian or Alaskan Native, and 1.60\% other or a race that was not listed.

Materials and Procedure. Participants were asked to list their religious affiliation as a category (e.g., atheist, Christian, or Jewish). Participants also reported on their levels of anger in relation to the commonly used Buss-Perry Trait Anger Scale (Buss \& Perry, 1992). This scale taps trait anger or the extent to which individuals become angry across situations and contexts; it measures anger in terms of a personality trait. The scale consists of seven items (e.g., "I have trouble controlling my temper") rated along a 5-point continuum $(1=$ strongly disagree; $5=$ strongly agree). We averaged the items to form a measure of trait anger $(\alpha=.78 ; M=2.20 ; S D=$ 0.68). The participants completed other questionnaires and tasks not related to the current hypothesis.

\section{Results and Discussion}

Seventy participants classified themselves as atheists and 757 participants classified themselves as believers or theists (a Christian or Jewish faith). The remaining 182 participants categorized themselves as something other than an atheist or theist (e.g., a Hindu or they chose an other category). We used a one-way ANOVA to examine whether atheists had higher trait anger than theists. We did not find an effect of religious category, $F(1,825)=0.12, p=.73$; the 
trait anger means of the atheists $(M=2.23 ; S D=0.76)$ and theists $(M=2.20 ; S D=0.68)$ were similar. These results were nearly identical when we compared atheists to everyone else in the sample, $F(1,1007)=0.13, p=.72$; the trait anger means of the atheists $(M=2.23 ; S D=0.76)$ and everyone else $(M=2.20 ; S D=0.68)$ were similar.

We next examined the equivalency of the trait anger means between atheists and believers and atheists and everyone else using the equivalency between means testing procedures of Rogers, Howard, and Vessey (1993). We found that the differences between the atheist and believer groups and the atheist and everyone else groups were within $10 \%$ of the smaller mean (approximately .22) in each case, $p$ s $<.05$. In other words, the means were equivalent. Both ANOVA and equivalency testing procedures revealed that, when defined in a strictly categorical sense, atheists do not appear to be angrier than other individuals.

\section{Study 5}

Study 4 revealed that atheists were not higher in trait anger than believers in God. Even though the study was adequately powered, additional data are warranted given that null relations were obtained. For power-related considerations, and because the results could be different, more continuous measures of belief in God were used in Studies 5-7. In Study 5, participants completed two measures of belief in God and two measures of trait anger. The results of Study 4 led us to believe that we would not find a significant relationship between belief in God and trait anger.

\section{Method}

Participants. Participants were 89 Gettysburg College undergraduates (49 females; age $M=18.67$ years; $S D=2.52$ years). The self-reported race breakdown of participants was as follows: 92.10\% Caucasian, 2.20\% African-American, 2.20\% Asian or Pacific Islander, 1.10\% 
Hispanic, and $2.20 \%$ other or a race that was not listed. We also collected a categorical measure of religiosity. The breakdown of participants' categorical religiosity was as follows: $66.30 \%$ Christian, $7.90 \%$ atheist, $6.70 \%$ agnostic, $5.60 \%$ Jewish, and $13.50 \%$ other or a category that was not listed.

Materials and Procedure. Participants completed tasks and questionnaires (many of which were not relevant to the present studies) on a computer. Participants completed four trait scales relevant to the present study. To assess belief in God, participants completed the Nearness to God Scale (Gorsuch \& Smith, 1983), which has six items rated on a 4-point continuum (1= strong disagreement; 4 = strong agreement). The items were averaged to form a belief in God score $(\alpha=.93 ; M=2.62 ; S D=0.90)$. Although the scale is labeled Nearness to God, the items tap belief in God ("God is very real to me", "Because of his presence, we can know that God exists"). Indeed, Toburen and Meier (2010) found that self-identified theists scored much higher on this scale than self-identified atheists $(d=1.30)$. Nonetheless, we also used the face-valid and more direct belief in God measure from Study 3: "I believe God exists" ( 1 = strongly disagree; 9 = strongly agree; $M=5.94 ; S D=2.77)$.

To measure anger, participants completed the Buss-Perry Trait Anger Scale (Buss \& Perry, 1992) used in Study 4 as well as the commonly used Spielberger Trait Anger scale (Spielberger, 1988), which consists of 10 items (e.g., "I have a fiery temper”) rated along a 4point continuum $(1=$ almost never; $4=$ almost always $)$. The items were averaged to form two scores, Buss-Perry scale $(\alpha=.79 ; M=2.11 ; S D=0.62)$; Spielberger scale $(\alpha=.82 ; M=1.88 ; S D$ $=0.47)$.

\section{Results and Discussion}

We computed Pearson correlations to determine the direction and strength of relations 
between belief in God and trait anger. As shown in Table 1, neither belief in God measure was significantly related to either trait anger measure. Not only were these correlations nonsignificant, but they tended to be in the opposite direction of the angry-atheist stereotype. Study 5 provides converging validity for the idea that the angry-atheist stereotype does not appear to be accurate.

\section{Study 6}

We wanted to substantiate the findings of Study 5 using a more generalizable sample of individuals in the U.S. Study 5 consisted of college undergraduates. Such individuals, typically away from their parents for the first time, are likely to question prior religious beliefs (Brown \& Lowe, 1951). Accordingly, it was deemed important to examine relations between belief in God and trait anger among an older group of individuals. Participants from Amazon.com's Mechanical Turk completed the same questionnaires from Study 5. We did not expect to find significant relationships between belief in God and anger.

\section{Method}

Participants. Participants were 108 individuals ( 73 females; age $M=34.37$ years; $S D=$ 13.03 years) who lived in 28 different U.S. states. The self-reported race breakdown of participants was as follows: 79.60\% Caucasian, 13.90\% Asian or Pacific Islander, 4.60\% Hispanic, and $1.90 \%$ African-American. We also collected a categorical measure of religiosity. The breakdown of participants' categorical religiosity was as follows: $63.00 \%$ Christian, $16.70 \%$ agnostic, $8.30 \%$ atheist, $1.90 \%$ Jewish, $1.90 \%$ Buddhist, $0.90 \%$ Hindu, and $7.40 \%$ other or a category that was not listed.

Materials and Procedure. The participants completed the same scales administered in Study 5 as well as other questionnaires not relevant to this study. They completed the Nearness 
to God $(\alpha=.97 ; M=2.71 ; S D=1.12)$, direct belief in God $(M=6.27 ; S D=3.05)$, Spielberger $(\alpha$ $=.87 ; M=1.77 ; S D=0.53)$, and Buss-Perry $(\alpha=.88 ; M=2.42 ; S D=0.82)$ scales.

\section{Results and Discussion}

In this more diverse sample in terms of age and location, the results were similar to Study 5. As shown in Table 1, neither belief in God measure significantly correlated with either measure of trait anger. However, the two belief in God measures were strongly correlated as were the two trait anger measures, which coincides with the results of Study 5. Accordingly, variations in belief in God appear non-predictive of trait anger among an older sample.

\section{Study 7}

Studies 4-6 examined belief in God and trait anger. People higher in trait anger have more experiences of state or momentary anger as well (Deffenbacher, 1992). State anger, though, is particularly apparent in aversive or provoking contexts (Berkowitz \& Harmon-Jones, 2004). In order to provide additional converging validity to Studies 4-6, we assessed belief in God and state anger following an anger induction in Study 7. We hypothesized that state anger would be higher following an anger-induction manipulation, but we did not expect belief in God to have an influence on this effect.

\section{Method}

Participants. Participants were 71 Gettysburg College undergraduates (43 females; age $M=18.72$ years; $S D=1.09$ years). The original sample included 76 participants, but 5 participants were dropped because of incomplete data or because they did not complete the task properly. The self-reported race breakdown of participants was as follows: $94.40 \%$ Caucasian, 4.20\% African-American, and 1.40\% American Indian or Alaskan Native. We also collected a categorical measure of religiosity. The breakdown of participants' categorical religiosity was as 
follows: $66.20 \%$ Christian, $9.90 \%$ atheist, $8.50 \%$ agnostic, $7.00 \%$ Jewish, and $8.50 \%$ other or a category that was not listed.

Materials and Procedure. Belief in God was assessed in terms of the Nearness to God Scale $(\alpha=.94 ; M=2.74 ; S D=0.95)$, which correlated strongly with the direct belief in God measure in Studies 5 and 6. Participants also completed a state anger scale after the manipulation. They rated their current feelings across six items (e.g., angry, hostile) of the PANAS-X State Anger Scale (Watson \& Clark, 1994) using an 11-point response scale $(0=$ not at all; $10=$ extremely). We averaged across these markers to quantify state anger $(\alpha=.81 ; M=$ $1.57 ; S D=1.54)$.

The emotion induction literature has shown that autobiographical writing manipulations are effective in targeting an emotional state of interest (Lerner \& Keltner, 2001; Moons \& Mackie, 2007) and we, therefore, used such a manipulation. By random assignment, individuals were asked to spend 6 minutes writing about a previous event that had made them extremely angry (the anger induction condition) or about their activities during the previous day (the control condition). Subsequently, individuals reported on their momentary anger using the PANAS-X scales. They also completed the Nearness to God scale.

\section{Results and Discussion}

A General Linear Model analysis was conducted with state anger as the dependent variable and the anger induction and $z$-scored belief in God as the independent variables. As expected, participants in the anger condition reported more state anger $(M=2.00 ; S D=1.79)$ than participants in the control condition $(M=1.14 ; S D=1.09), F(1,67)=5.81, p=.019$, partial eta squared $=.08$. This effect reveals that the anger manipulation was effective. The main effect for belief in God was not significant, $F(1,67)=1.95, p=.17$ (the predicted means were in the 
opposite direction of the angry-atheist stereotype). Importantly, belief in God did not moderate or buffer the impact of the anger manipulation, $F<1$. For the sake of complete reporting, Figure 2 displays estimated means (Aiken \& West, 1991) as a function of condition and low (-1 SD) versus high $(+1 S D)$ levels of beliefs in God. Accordingly, it appears equally easy to induce anger among individuals low versus high in belief in God.

\section{General Discussion}

Our studies revealed that people believe that atheists are angrier than believers, people in general, and another minority group of comparable size. Yet, we did not find any evidence to suggest that atheists - or those people believing in God to a lesser extent - are particularly angry individuals. Below, we discuss implications, outline some future directions of research, and address potential limitations.

\section{Implications and Future Considerations}

First and foremost, our results suggest that the idea of the angry-atheist is a myth. Although people espouse the view that atheists are angry, and although such associations are embedded at an implicit level of cognition, the idea simply does not appear to be true. For this reason, we would encourage people to challenge this idea when expressed by communication partners or when encountered in popular media sources. It is a misperception that should be corrected rather than endorsed.

Indeed, it is important to correct negative stereotypes that are not true because they can have unfortunate consequences. For example, research has shown that perceiving other people as angry can make us hostile and set the stage for conflicts that need not happen (Berkowitz, 2012; Orobio de Castro et al., 2002). Such conflicts may be especially likely with atheists because this group appears to be stigmatized in some unique ways (Gervais et al., 2011; Gervais 
\& Norenzayan, 2012b) and because society does not seem to censure the disparagement of atheists in the same way that it might censure the disparagement of other minorities. Stereotypes are detrimental to stigmatized groups because they create expectations about how people should treat out-group individuals (Bahns \& Branscombe, 2010). Future research should focus on whether the angry-atheist stereotype actually drives discriminatory behavior. For example, does an angry-atheist perception correlate with a tendency to withhold rights from atheists? Or, perhaps, does an angry-atheist perception lead others to start arguments with atheists leading to an induced confirmation of the stereotype? In sum, the angry-atheist perception might partially drive discriminatory behavior against atheists. Studies that assess both variables will be useful in examining this idea.

Our studies were not designed to identify the factors that drive an angry-atheist stereotype. Indeed, our research question was purposely simple: does the angry-atheist stereotype exist and to what extent is it accurate? However, we can speculate on some potential causes. One potential cause relates to passionate atheists who discuss religion in public settings. These individuals are typically open, forceful, and fervent about their beliefs. Such discussions about religion and God go against what most Americans believe. These portrayals could drive people's beliefs that atheists are angry. Furthermore, media brings to mind this stereotype when they use the term "angry atheist" to describe this passionate communication style.

Another potential cause relates to perceivers potentially projecting their own anger onto atheists. Religion is a major source of meaning and comfort to a large number of Americans (Pew Research Center, 2008). Atheists may be perceived to threaten this source of meaning, thereby triggering anger and the defensive sorts of processes identified by existential psychologists (e.g., Solomon, Greenberg, \& Pyszczynski, 2000). Research has indeed shown 
that people can project anger onto other individuals. For example, Schimel, Greenberg, and Martens (2003) found that participants who were told that they scored high versus low on a measure of anger subsequently rated a hypothetical person as higher in anger. Other work has shown that participants who underwent an angry versus a sad or neutral mood induction were more likely to use stereotypes when making judgments about a hypothetical individual (Bodenhausen, Sheppard, \& Kramer, 1994). Furthermore, prominent models of aggression suggest that experiencing provocation and anger can bias people into perceiving subsequent events in a hostile manner (Berkowitz, 2012; Meier \& Wilkowski, 2013). Future work should examine if anger in perceivers is related to the tendency to engage in the angry-atheist stereotype. For example, researchers could examine the extent to which state or trait anger predicts the tendency to use the angry-atheist stereotype.

It is also possible that there is a type of "focalism" to the angry-atheist stereotype and to why it is not correct. Atheists are a small minority and many people may have few interactions with them (Zuckerman, 2007). Research suggests that it is precisely under such conditions that stereotypes can thrive even if incorrect (Dovidio, Gaertner, \& Kawakami, 2003). That is, they thrive when people have preconceived ideas about a group of people that are not updated in the context of "individuating" information concerning particular people from that group. The same principles can explain why negative stereotypes could persist even with relatively friendly encounters because we are often unaware of the religious beliefs of the people with whom we interact. Such a tendency can be magnified considering that people tend to seek information that confirms rather than disconfirms their initial beliefs (Nickerson, 1998).

We assessed trait anger because trait anger encompasses the most general anger-related tendencies of individuals (Wilkowski \& Robinson, 2010). We also assessed state anger in 
relation to prototypical elicitors of it (Lerner \& Keltner, 2001). However, we cannot conclude that there will never be differences in anger between believers and non-believers. Indeed, it would be interesting to examine anger in the context of religious settings or disagreements. On the one hand, one might predict that, in these contexts at least, atheists might experience anger more intensely in reaction to what they perceive to be an erroneous belief system. On the other hand, though, there are reasons for thinking that belief in God can serve a defensive function and that, for this reason, believers might become more angry if they think that their beliefs are being challenged (Solomon et al., 2000). Creative research designs would be needed to examine this more specific research question, though the results would have value in extending the present analysis in a more nuanced fashion.

\section{Limitations}

Our studies included some limitations that are worth discussing. First, larger sample sizes can be advocated for some purposes at least. In more particular terms, the statistical power in Study 7 was lower than the other studies and would benefit from a larger sample size (though note that the direction of the believer/non-believer difference was counter to the angry-atheist stereotype). Second, some of the dependent measures involved one item. Although single-item measures of religious orientation are often used, they may not be the most reliable ones. Third, with the exception of Study 2, all of our dependent measures were self-reported in nature. We do regard this reliance on self-report as a limitation and would use behavioral paradigms, observer reports, or peer reports in extensions of the present work. Fourth, we briefly remind the reader that block order was not counterbalanced in Study 2. Doing so could be useful in supporting the results of Study 2 (though see Nosek et al., 2003). In the context of these 
limitations, we emphasize the convergence of the conclusions across multiple studies using multiple methods and sample types.

\section{Summary and Conclusions}

We examined the prevalence and accuracy of an angry-atheist stereotype in seven studies. We found that people believe atheists are angrier than believers, people in general, and another minority group, both explicitly and implicitly. However, none of our studies supported the idea that atheists are angrier than other individuals. Our work, in sum, suggests that the angry-atheist stereotype exists, but that it does not match reality. Dissemination of the present results may be useful in correcting misperceptions while averting potential unwarranted and harmful consequences. 
Author Notes

Brian P. Meier is an associate professor of psychology at Gettysburg College

Adam K. Fetterman is a post-doctoral researcher at the Knowledge Media Research Center in Tübingen, Germany

Michael D. Robinson is a professor of psychology at North Dakota State University

Courtney M. Lappas is an assistant professor of biology at Lebanon Valley College 


\section{References}

Adams, G. (2011). Santa Monica's angry atheists declare a real war on Christmas. Retrieved June $6^{\text {th }}, 2013$ from http://www.independent.co.uk/news/world/americas/santa-monicasangry-atheists-declare-a-real-war-on-christmas-6276970.html.

Aiken, L. S., \& West, S. G. (1991). Multiple regression: Testing and interpreting interactions. Newbury Park, CA: Sage Publications.

Aron, A., Aron, E. N., \& Coups, E. J. (2009). Statistics for psychology (5 ${ }^{\text {th }}$ Edition). Upper Saddle River, NJ: Prentice Hall.

Bahns, A. J., \& Branscombe, N. R. (2010). Effects of legitimizing discrimination against homosexuals on gay bashing. European Journal of Social Psychology, 41, 388-396. doi: 10.1002/ejsp.784

Berkowitz, L. (1993). Aggression: Its causes, consequences, and control. New York: McGraw Hill.

Berkowitz, L. (2012). A different view of anger: The cognitive-neoassociation conception of the relation of anger to aggression. Aggressive Behavior, 38, 322-333. doi: 10.1002/ab.21432

Berkowitz, L., \& Harmon-Jones, E. (2004). Toward an understanding of the determinants of anger. Emotion, 4, 107-130. doi: 10.1037/1528-3542.4.2.107

Bodenhausen, G. V., Sheppard, L. A., \& Kramer, G. P. (1994). Negative affect and social judgment: The differential impact of anger and sadness. European Journal of Social Psychology, 24, 45-62. doi: 10.1002/ejsp.2420240104

Brown, D. G., \& Lowe, W. L. (1951). Religious beliefs and personality characteristics of college students. Journal of Social Psychology, 33, 103-129. doi:

$10.1080 / 00224545.1951 .9921803$ 
Buss, A. H., \& Perry, M. (1992). The aggression questionnaire. Journal of Personality and Social Psychology, 63, 452-459. doi=10.1037/0022-3514.63.3.452

Christina, G. (2012). Why are you atheists so angry? 99 things that piss off the Godless. San Francisco, CA: Dirty Heathen Publishing.

Cohen, J. (1992). A power primer. Psychological Bulletin, 112, 155-159. doi:10.1037/00332909.112.1.155

Correll, J., Park, B., Judd, C. M., \& Wittenbrink, B. (2002). The police officer's dilemma: Using ethnicity to disambiguate potentially threatening individuals. Journal of Personality and Social Psychology, 83, 1314-1329. doi: 10.1037/0022-3514.83.6.1314

Deffenbacher, J. L. (1992). Trait anger: Theory, findings, and implications. In C. D. Spielberger \& J. N. Butcher (Eds.), Advances in personality assessment, Vol. 9. (pp. 177-201). Hillsdale, NJ: Erlbaum.

Diener, E., Tay, L., \& Myers, D. G. (2011). The religion paradox: If religion makes people happy, why are so many dropping out? Journal of Personality and Social Psychology, 101, 1278-1290. doi:10.1037/a0024402

Dovidio, J. F., Gaertner, S. L., \& Kawakami, K. (2003). Intergroup contact: The past, present, and the future. Group Processes and Intergroup Relations, 6, 5-21. doi: $10.1177 / 1368430203006001009$

Edgell, P., Gerteis, J., \& Hartmann, D. (2006). Atheists as “other”: Moral boundaries and cultural membership in American society. American Sociological Review, 71, 211-234. doi: $10.1177 / 000312240607100203$ 
Ehrlich, H. J., \& Van Tubergen, G. N. (1971). Exploring the structure and salience of stereotypes. Journal of Social Psychology, 83, 113-127. doi:10.1080/00224545.1971.9919979

Fazio, R. H., \& Olson, M. A. (2003). Implicit measures in social cognition research: Their meaning and use. Annual Review of Psychology, 54, 297-327. doi: 10.1146/annurev.psych.54.101601.145225

Furnham, A., Meader, N., \& McClelland, A. (1998). Factors affecting nonmedical participants' allocation of scarce medical resources. Journal of Social Behavior and Personality, 12, 735-736.

Gellman, M. (2006). Trying to understand angry-atheists. Retrieved June $6^{\text {th }}, 2013$ from www.newsweek.com/2006/04/25/trying-to-understand-angry-atheists.html.

Gervais, W. M., \& Norenzayan, A. (2012a). Like a camera in the sky? Thinking about God increases public self-awareness and socially desirable responding. Journal of Experimental Social Psychology, 48, 298-302. doi:10.1016/j.jesp.2011.09.006

Gervais, W. M., \& Norenzayan, A. (2012b). Reminders of secular authority reduce believers' distrust of atheists. Psychological Science, 23, 483-491. doi: 10.1177/0956797611429711

Gervais, W. M., Shariff, A. F., \& Norenzayan, A. (2011). Do you believe in atheists? Distrust is central to anti-atheist prejudice. Journal of Personality and Social Psychology, 101, 1189-1206. doi: 10.1037/a0025882

Gorsuch, R. L., \& Smith, C. S. (1983). Attributions of responsibility to God: An interaction of religious beliefs and outcomes. Journal for the Scientific Study of Religion, 22, 340-352. 
Greenwald, A. G., Banaji, M. R., Rudman, L. A., Farnham, S. D., Nosek, B. A., \& Mellott, D. S. (2002). A unified theory of implicit attitudes, stereotypes, self-esteem, and self-concept. Psychological Review, 109, 3-25. doi: 10.1037//0033-295X.109.1.3

Greenwald, A. G., McGhee, D. D., \& Schwartz, J. L. K. (1998). Measuring individual differences in implicit cognition: The implicit association test. Journal of Personality and Social Psychology, 74, 1464-1480. doi:10.1037/0022-3514.74.6.1464

Greenwald, A. G., Poehlman, T. A., Uhlmann, E., \& Banaji, M. R. (2009). Understanding and using the Implicit Association Test: III. Meta-analysis of predictive validity. Journal of Personality and Social Psychology, 97, 17-41. doi: 10.1037/a0015575

Inzlicht, M., \& Tullett, A. M. (2010). Reflecting on God: Religious primes can reduce neurophysiological response to errors. Psychological Science, 21, 1184-1190. doi: $10.1177 / 0956797610375451$

Jones, J. (2007). Some Americans reluctant to vote for Mormon, 72-year-old presidential candidates. Retrieved June $6^{\text {th }}, 2013$ from www.gallup.com/poll/26611/some-americansreluctant-vote-mormon-72yearold-presidential-candidates.aspx.

Jonas, E., \& Fischer, P. (2006). Terror management and religion: Evidence that intrinsic religiousness mitigates worldview defense following mortality salience. Journal of Personality and Social Psychology, 91, 553-567. doi: 10.1037/0022-3514.91.3.553

Koenig, H. G., \& Larson, D. B. (2001). Religion and mental health: evidence for an association. International Review of Psychiatry, 13, 67-78. doi:10.1080/09540260124661

Lerner, J. S., \& Keltner, D. (2001). Fear, anger, and risk. Journal of Personality and Social Psychology, 81, 146-159. doi. 10.1037//O022-3514.81.1.146 
Lurie, A. (2010). Anatomy of an angry atheist. Retrieved on June $6^{\text {th }}, 2013$ from www.huffingtonpost.com/alan-lurie/anatomy-of-an-angry-athei_b_668720.html.

Meier, B. P., Robinson, M. D., Carter, M. S., \& Hinsz, V. B. (2010). Are sociable people more beautiful? A zero-acquaintance analysis of agreeableness, extraversion, and attractiveness. Journal of Research in Personality, 44, 293-296. doi: org/10.1016/j.jrp.2010.02.002

Meier, B. P., \& Wilkowski, B. M. (2013). Reducing the tendency to aggress: Insights from social and personality psychology. Social and Personality Psychology Compass, 7, 343-354. doi: $10.1111 / \mathrm{spc} 3.12029$

Moons, W. G., \& Mackie, D. M. (2007). Thinking straight while seeing red: The influence of anger on information processing. Personality and Social Psychology Bulletin, 33, 706720. doi: $10.1177 / 0146167206298566$

Newport, F. (2011). More than 9 in 10 Americans continue to believe in God. Retrieved June $6^{\text {th }}$, 2013 from http://www.gallup.com/poll/147887/americans-continue-believe-god.aspx.

Nickerson, R. S. (1998). Confirmation bias: A ubiquitous phenomenon in many guises. Review of General Psychology, 2, 175-220. doi: 10.1037/1089-2680.2.2.175

Nosek, B. A., Greenwald, A. G., \& Banaji, M. R. (2005). Understanding and using the implicit association test: II. Method variables and construct validity. Personality and Social Psychology Bulletin, 31, 166-180. doi: 10.1177/0146167204271418

Orobio de Castro, B., Veerman, J. W., Koops, W., Bosch, J. D., \& Monshouwer, H. J. (2002). Hostile attribution of intent and aggressive behavior: A meta-analysis. Child Development, 73, 916-934. doi: 10.1111/1467-8624.00447 
Paolacci, G., Chandler, J., \& Ipeirotis, P. G. (2010). Running experiments on Amazon Mechanical Turk. Judgment and Decision Making, 5, 411-419.

Pew Research Center. (2008). U.S. religion landscape survey. Religious affiliation: Diverse and dynamic. February 2008. Washington, DC: Pew Research Center.

Puhl, R. M., \& Heuer, C. A. (2010). Obesity stigma: Important considerations for public health. American Journal of Public Health, 100, 1019-1028. doi: 10.2105/AJPH.2009.159491

Rogers, J. L., Howard, K. I., \& Vessey, J. T. (1993). Using significance tests to evaluate equivalence between two experimental groups. Psychological Bulletin, 113, 553-565. doi: 10.1037/0033-2909.113.3.553

Rudman, L. A., \& Ashmore, R. D. (2007). Discrimination and the implicit association test. Group Processes \& Intergroup Relations, 10, 359-372. doi: 10.1177/1368430207078696

Schimel, J., Greenberg, J., \& Martens, A. (2003). Evidence that projection of a feared trait can serve a defensive function. Personality and Social Psychology Bulletin, 29, 969-979. doi: $10.1177 / 0146167203252969$

Shaha, A. (2010). Thank god (and Richard Dawkins) I'm no longer an 'angry atheist.' Retrieved June $6^{\text {th }}, 2013$ from www.guardian.co.uk/science/blog/2010/sep/09/god-richard-dawkinsangry-atheist.

Shariff, A. F., \& Norenzayan, A. (2007). God is watching you: Priming God concepts increases prosocial behavior in an anonymous economic game. Psychological Science, 18, 803809. doi: 10.1111/j.1467-9280.2007.01983.x

Solomon, S., Greenberg, J., \& Pyszczynski, T. (2000). Pride and prejudice: Fear of death and social behavior. Current Directions in Psychological Science, 9, 200-204. doi: 10.1111/1467-8721.00094 
Spencer, S. J., Steele, C. M., \& Quinn, D. M. (1999). Stereotype threat and women's math performance. Journal of Experimental Social Psychology, 35, 4-28. doi: org/10.1006/jesp.1998.1373

Spielberger, C. D. (1988). Manual for the state-trait anger expression inventory. Odessa, FL: PAR.

Toburen, T., \& Meier, B. R. (2010). Priming God-related concepts increases anxiety and task persistence. Journal of Social and Clinical Psychology, 29, 127-143. doi: $10.1521 /$ jscp.2010.29.2.127

Watson, D., \& Clark, L. A. (1994). The PANAS-X: Manual for the positive and negative affect schedule-Expanded Form. Iowa City, IA: University of Iowa.

Wilkowski, B. M., \& Robinson, M. D. (2010). The anatomy of anger: An integrative cognitive model of trait anger and reactive aggression. Journal of Personality, 78, 9-38. doi: 10.1111/j.1467-6494.2009.00607.x

Zuckerman, P. (2007). Atheism: Contemporary numbers and patterns. In M. Martin (Ed.), The Cambridge companion to atheism (pp. 47-66). Cambridge, England: Cambridge University Press.

Zuckerman, P. (2009). Atheism, secularity, and well-being: How the findings of social science counter negative stereotypes and assumptions. Sociology Compass, 3/6, 949-971. doi: 10.1111/j.1751-9020.2009.00247.x 
Table 1

Correlations among Variables, Study 5 (Above the Diagonal) and Study 6 (Below the Diagonal)

\begin{tabular}{ccccc}
\cline { 2 - 5 } & $\begin{array}{c}\text { Nearness to } \\
\text { God }\end{array}$ & $\begin{array}{c}\text { Direct God } \\
\text { Belief }\end{array}$ & $\begin{array}{c}\text { Buss-Perry } \\
\text { Trait Anger }\end{array}$ & $\begin{array}{c}\text { Spielberger } \\
\text { Trait Anger }\end{array}$ \\
\hline Nearness to God & - & $.62^{*}$ & .06 & .13 \\
Direct God Belief & $.93^{*}$ & - & .01 & -.01 \\
Buss-Perry Trait Anger & -.04 & -.05 & - & $.71^{*}$ \\
Spielberger Trait Anger & -.07 & -.08 & $.77^{*}$ & - \\
\hline
\end{tabular}

$*=p<.01$ 


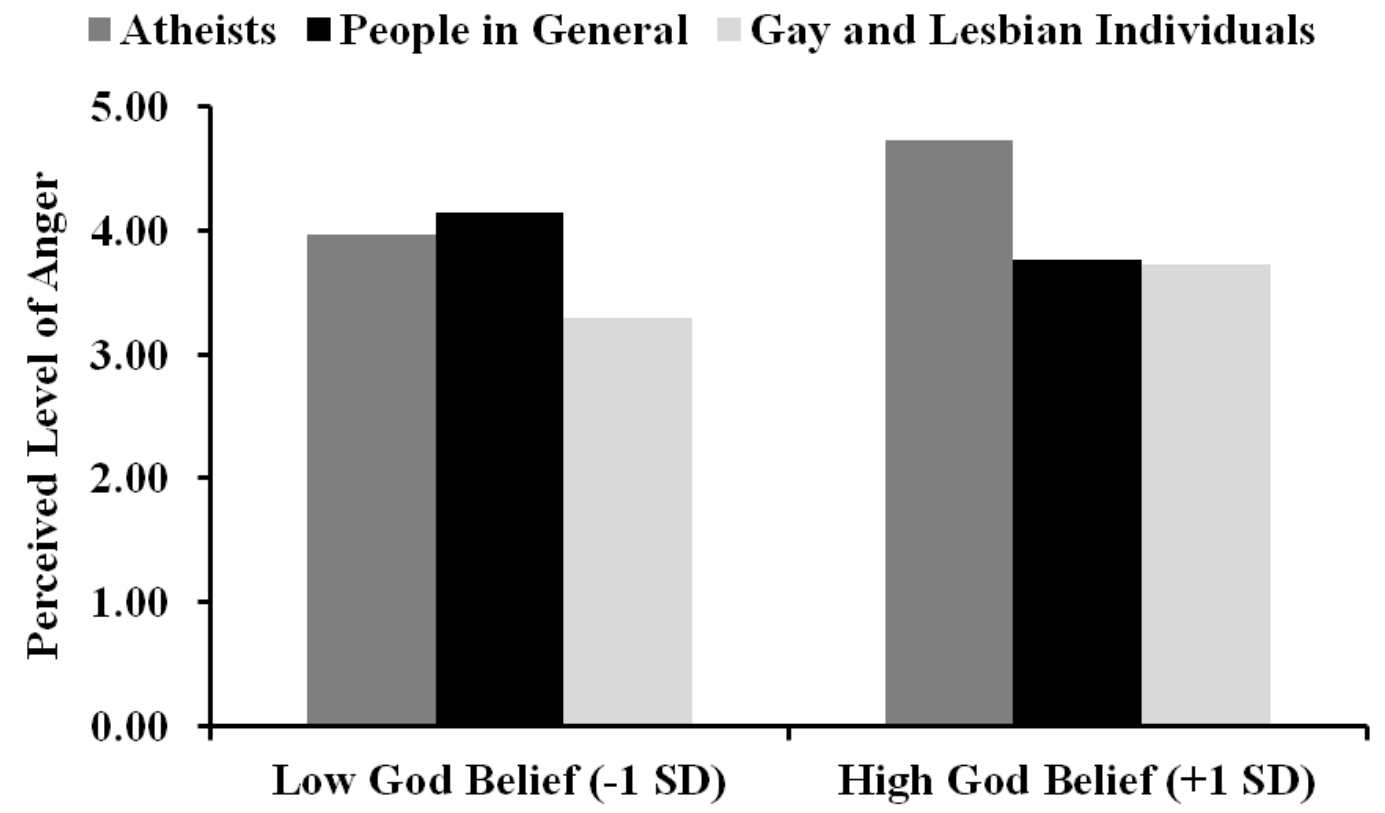

Figure 1.

Predicted Perceived Anger of Atheists, People in General, and Gay and Lesbian Individuals by Belief in God, Study 3 


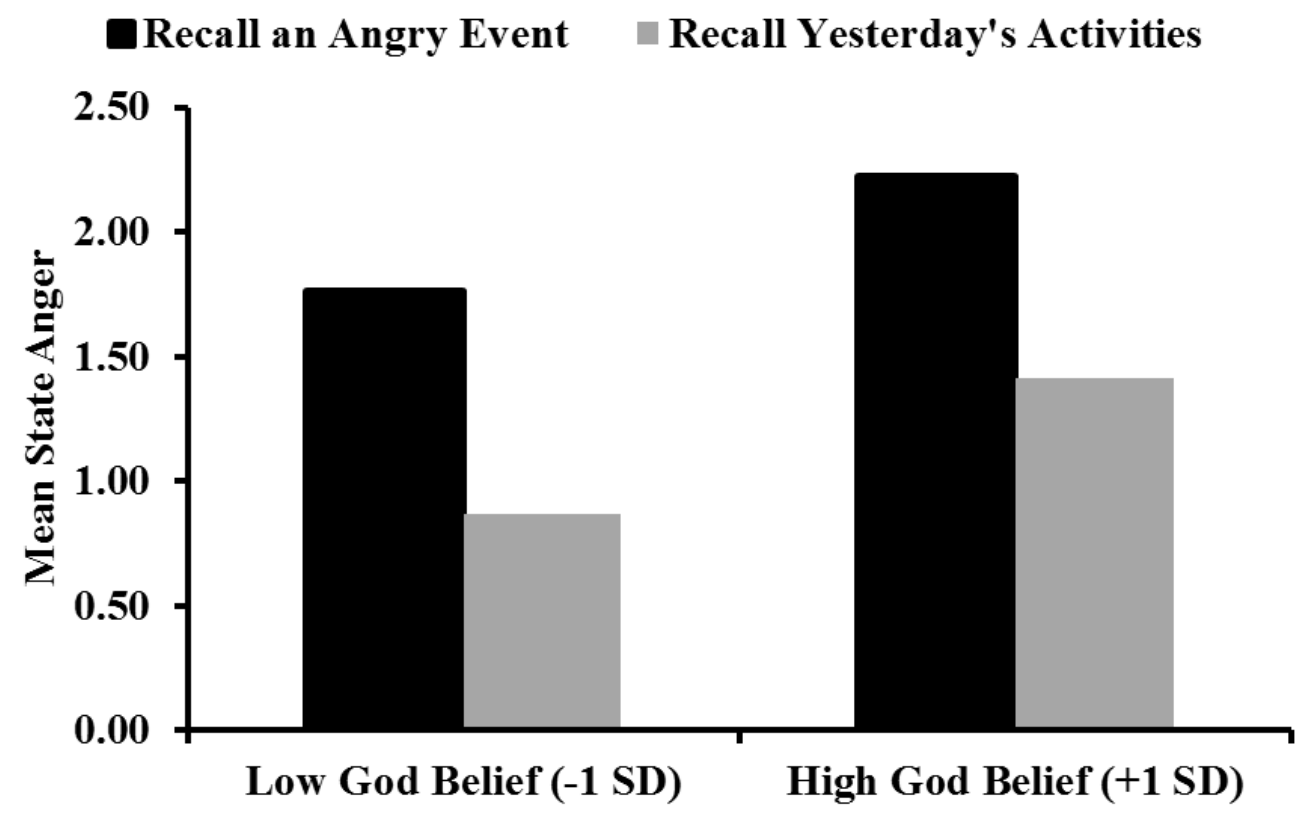

Figure 2.

Predicted State Anger by Belief in God and the Anger Manipulation Condition, Study 7 